Petter / Gtrafgefegbud 



\title{
Gtrafge $\mathfrak{e} \mathfrak{e} \mathfrak{b u d}$
}

mit Crläuterungen und seifpielen

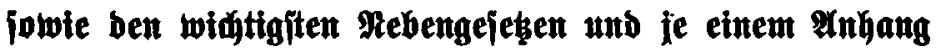

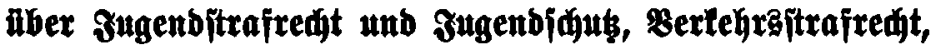
Dronungstwibrigfetten unb Strajprozebredit

\author{
bon \\ Dr. Walter Petter\&
}

Santogeridgtšrat a. D.

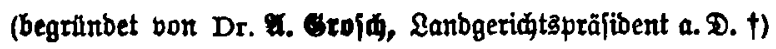

Sâr Stubium, Bolizei, und Beridtoparis

Dreiunbzwamigfte Fuflage

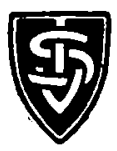

1955

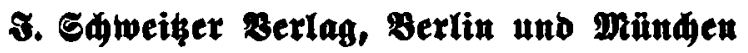


Sab, Drud unb Bimbearbeiten:

Dr. \&. \$. Datterer \& Bie. - Jumbaber Sellier - Greifing

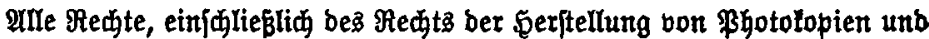
Mitrofilmen, vorbehalten 